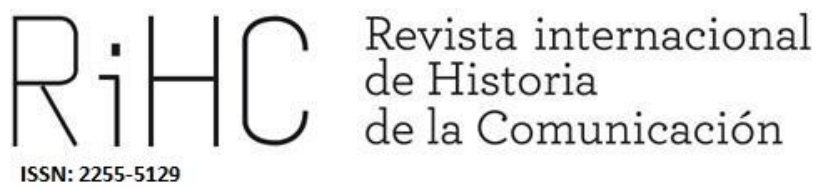

\title{
MEDIACIONES DE LA \\ VIOLENCIA FRANQUISTA EN EL \\ CINE ESPAÑOL DEL SIGLO XXI
}

\section{Mediations of francoist violence in the XXI century Spanish movies}

DOI: https://dx.doi.org/10.12795/RiHC.2020.i15.01

Recibido: $30-9-2020$

Aceptado: 11-11-2020

Publicado: $30-12-2020$

Aurora Ducellier

Université Sorbonne Nouvelle Paris 3, Francia

aurore.ducellier@casadevelazquez.org

ORCID (I) 0000-0001-9105-137X

Resumen: Desde La lengua de las mariposas (1999) hasta Mientras dure la guerra (2019), un creciente número de ficciones y documentales cinematográficos representaron la represión franquista en un contexto de recuperación de la memoria histórica. Así, al menos unas cuarenta películas de este principio de siglo aluden a los maquis, los presos y las víctimas en su conjunto para denunciar mediáticamente la violencia de la dictatura. El cine se hace mediador de la memoria en la escena pública y pretende modificar, mediante una construcción plural, la recepción de este periodo represivo en la memoria 
colectiva. Proponemos explorar la evolución del mensaje acerca de la violencia franquista en el cine de estas dos últimas décadas, a través de una tipología de sus víctimas, de las representaciones de la represión y de los relatos ideológicos que en ellas se enfrentan: mediante las técnicas cinematográficas y los personajes, así como a través del uso y la alteración de los símbolos de esta violencia, que la posicionan en una zona de recepción movediza.

Palabras clave: Cine español, violencia, franquismo, mediaciones.

\begin{abstract}
From Butterfly's Tongue (1999) to While at War (2019), a growing number of cinematographic fictions and documentaries depicted Franco's repression in a context of recovery of historical memory. Thus, at least forty movies from this beginning of the century allude to the maquis, prisoners and victims as a whole to denounce the violence of the dictatorship in the media. The cinema mediates memory in the public scene and tries to modify, through a plural construction, the reception of this repressive period in the collective memory. We propose to explore the evolution of the message about Franco's violence in the cinema of these last two decades, with a typology of the victims, the representations of repression and the ideological narratives that are faced in them: through cinematographic techniques and characters, as well as the use and alteration of the symbols of this violence, which place it in a moving reception area.
\end{abstract}

Keywords: Spanish movies, violence, Francoism, mediations.

\title{
Introducción
}

Cuando se estrenó en España la última película de Amenábar, Mientras dure la guerra, un biopic sobre las vivencias de Unamuno en la Salamanca de 1936, se desató una polémica ideológica, que se extendía desde derecha -la Fundación Millán Astray ha puesto una denuncia (Núñez, 2019)- hasta la izquierda (Piña, 2019). Sin embargo, estas críticas no impidieron que esta película obtuviera cinco Goyas. Desde La lengua de las mariposas en 1999 hasta el estreno de Mientras dure la guerra en 2019 -unidas por un mismo compositor de banda sonora, Amenábar, y un mismo mensaje, la represión de la intelectualidad al tomar el poder el fascismo español- al menos cuarenta películas han hecho de la represión franquista materia de ficción o documental, sobre todo a raíz de la Ley de Memoria Histórica, aprobada en 2007 y en proceso de ampliación. En efecto, esta inflación se hace más visible a partir de la segunda década: mientras que la filmografía en anexo recoge sólo doce películas desde 1999 hasta 2009, se estrenan más de veinte durante los diez años siguientes, destacando los periodos de 2010 a 2011 y, más recientemente, de 2018 a 2019, en que se estrenaron unas siete en dos años.

Estas obras mediáticas son intermedios culturales para el público: proporcionan, además de un setting dentro del boom cultural y literario de la memoria, un framing, que influye en la percepción de la guerra y de la posguerra que tienen los espectadores. 
A veces se evoca de manera breve o sutil, como se hace en la exitosa película $L a$ isla mínima, que alude a las secuelas de la violencia franquista en la Transición a través del pasado del policía que colaboró con la dictadura. De esta manera, el cine actúa como mediador de la memoria en la escena pública y contribuye a modificar la recepción de este periodo represivo en el inconsciente colectivo, incluso cuando procede mediante pinceladas.

Sin pretender ser exhaustivo y centrándose en las obras de ficción, este estudio analizará el relato y la denuncia de la violencia de la dictadura española en el cine del siglo XXI y se vertebrará en torno a cómo evoluciona el mensaje, desde su producción en las películas hasta su recepción por los espectadores. Se documentará, además del marco socio-cultural, la recepción de esta propuesta mediática con el número de entradas vendidas durante el año de estreno, y con los premios otorgados por la crítica. Recurriremos principalmente al método de análisis fílmico, pero también a la sociología de la comunicación, a la historia cultural y, por supuesto, a la historia del franquismo. Veremos que las mutaciones, renovadas a partir de 2010 y 2011, se pueden agrupar en tres grandes categorías: la diversificación de las víctimas y su feminización, la transformación de los verdugos y de los símbolos de esta violencia, y un reflejo cada vez más polarizado de los debates ideológicos en torno a la memoria histórica.

\section{Más allá de martirios y heroismos: una victimización más compleja y feminista}

Los relatos que se cuentan en las películas de ficción que nos interesan buscan una adhesión del espectador mediante la identificación propia de la mimesis. Con este fin, se observa una representación cada vez más diversa de las víctimas en el siglo XXI, un periodo de recuperación de la memoria en España con búsquedas familiares, por parte de los nietos en los años noventa, y de boom de la memoria en la narrativa (Javier Cercas, Alfons Cervera o Jordi Soler, por ejemplo). El cine se hace eco de esta mediatización de las voces hasta ahora silenciadas y surgen perfiles más variados de víctimas, en comparación con los de las décadas anteriores, como los artistas de iAy, Carmela! en 1990. No sólo aparecen víctimas habituales, como los maestros y niños de La lengua de las mariposas (1999), sino también dos tópicos aparentemente opuestos y cuya dimensión épica se cuestiona: los "mártires" (torturados, detenidos o asesinados) y los "héroes" (como los maquis y los topos). Asimismo, en un contexto de promoción de la igualdad de género, con las Leyes de 2004 y 2007, las mujeres cobran mayor protagonismo. 


\subsection{Víctimas represaliadas: ¿los "mártires" del franquismo?}

La cara más visible y patética del conjunto de víctimas que aparecen retratadas en las películas del siglo XXI para poner en tela de juicio la violencia franquista es, sin duda, la de los represaliados, cuyo sufrimiento puede ser escenificado a modo de martirio, para cumplir con las expectativas del espectador en busca de "sentimientos" y hasta de "formas agresivas" (Bordwell, 2003: 62-65). Su representación cinematográfica pretende ahondar en el conocimiento del pasado reciente de España, consolidando una tradición fílmica ya abundante desde la Transición (Gustrán Loscos, 2015: 465-468), y hacerse eco del debate memorialista impulsado por las asociaciones de víctimas en los años 2000, tras el pacto del silencio transicional a nivel sociopolítico. Proponemos aquí un recorrido tripartito, analizando algunos fotogramas significativos para esbozar una gradación de los castigos padecidos: primero, la tortura -incluída la violación- como agresión y humillación corporal, luego la detención como privación de libertad y, para terminar, el asesinato como forma pseudojudicial o extrajudicial de eliminar a los enemigos del régimen.

\subsubsection{Torturados/as y violadas}

Primero, cabe interesarse por las escenas de torturas y violaciones que pretenden ser mediaciones de la violencia franquista contada por los historiadores (Gómez Roda, 2005). Aunque son numerosos los ejemplos cinematográficos, desde El crimen de Cuenca (1979) hasta las torturas franquistas para acabar con ETA en El Lobo (2004) o la serie La línea invisible (2020), nos centraremos aquí en tres fotogramas que juegan con los efectos de luz y sombra para impactar al espectador (Bordwell, 2003: 152) y enfatizar su compasión hacia la víctima. El primero a nivel cronológico, de El Laberinto del Fauno de 2006, es un primer plano ${ }^{1}$ de la cara del torturado tartamudo, en el que destacan sus labios manchados de sangre que fallan en pronunciar la cifra tres, que supuestamente lo libraría de su torturador. La poca luz que entra por el subsuelo de la casa sirve para poner de realce la sangre, el sudor y la expresión de terror de la víctima.

Cinco años más tarde, en La Voz dormida, dos escenas sucesivas de torturas enmarcan la imagen de una Pepita desnuda y humillada en una celda y unen a los amantes en el dolor. La anteposición de las torturas femeninas a las masculinas permite renovar el cliché de las torturas en el cine sobre la violencia franquista y, además, dar más protagonismo a las mujeres que padecieron daños colaterales por amar a un antifranquista represaliado. En la segunda sesión de tortura, se realza el sufrimiento mediante la composición, ya que la curva de los brazos del verdugo aplicando electrodos

\footnotetext{
${ }^{1}$ Para los conceptos de narrativa y estilística audiovisual, véanse el análisis neoformalista $E /$ arte cinematográfico (Bordwell, 2003) y el Manual básico de lenguaje y narrativa audiovisual (Fernández Díez, 1999).
} 
desemboca en el grito del torturado Paulino. De nuevo, la poca luz sirve para dibujar los contornos del cuerpo doliente.

En la primera sesión de tortura, se vislumbra cierto compromiso feminista, ya desde la postura de dominación del policía, que se encuentra de pie ante su futura víctima. El dolor se expresa esta vez mediante el hilo de sangre en la boca de Pepita y el segundo grito fuera de campo, mientras el policía bebe en una taza. Destaca aquí el simbolismo sexual y maternal de los pechos maltratados, al igual que, en Las 13 Rosas, a Julia le pinchan y queman el seno. También se refuerza el pathos mediante la gradación del castigo padecido por Pepita: le dan una bofetada primero, luego le tiran del pelo, le arrancan la camisa, para finalmente aplicarle electrodos en el pecho.

En La trinchera infinita, mucho más reciente, vuelve a aparecer una mujer torturada, pero con una evolución substancial. En efecto, en el caso de Rosa, notamos una elipsis de las torturas que ocurren entre su detención y su vuelta a casa: al director le interesa más el resultado y, por tanto, la cámara se centra en una cara tumefacta y una cabeza con el pelo arrancado, enmarcadas por el agujero de su marido topo y alumbradas por la luz de su linterna. A juzgar por el comportamiento sexual extraño de Rosa tras esta vuelta, el espectador puede imaginar incluso que ha sido violada, pero en ningún momento se aclara el tipo de violencias padecidas durante la elipsis. Es como si esta mediación cinematográfica quisiera transmitir el silencio y el miedo que se cernía sobre las víctimas $y$, en particular, sobre las mujeres humilladas. Hemos visto, a través de algunas escenas de torturados y torturadas, cómo ha evolucionado este tópico del cine español reciente para reflejar de manera más sutil la violencia franquista. El análisis del siguiente grado de victimización, el de la detención, en el mismo periodo cinematográfico, también aporta indicaciones sociológicas sobre la demanda, siempre renovada, en materia de cine de la memoria.

\subsubsection{Detenidos/as y encarcelados/as}

José Luis Sánchez Noriega ha señalado el hambre, el hacinamiento, los castigos y los rituales impuestos pero, como contrapunto, la solidaridad, en particular en lo que a las prisiones de mujeres respecta (Sánchez Noriega, 2016: 320-321) como elementos comunes del cine penitenciario español, subgénero del cine histórico. Esta insistencia en la solidaridad puede interpretarse, aunque no sólo, como una estrategia para atraer al espectador hacia un subgénero en apariencia repelente, dentro de una cultura mediática que promueve mayoritariamente el entretenimiento: "la industria cultural sigue siendo la industria de la diversión” (Adorno, 1998: 181). De esta manera se puede explicar la elección del director de Las 13 Rosas (2007) a la hora de retratar el traslado de las protagonistas en camión hacia el juicio-farsa que les espera: en una visión romántica relativamente poco verosímil, las chicas se levantan para romper la falta de libertad de movimiento y sus manos apoyadas en el borde simbolizan estas limitaciones. 
Sin embargo, la película insiste reiteradamente en la solidaridad de estas trece víctimas frente a las condenas a muerte y en su alegría a toda prueba.

Si bien el personaje de Tensi, en La Voz dormida (2011), también encarna la solidaridad y la lucha junto a sus compañeras y a su hermana, los símbolos de su encierro se alejan ya del idealismo y de un compañerismo alegre. La famosa escena del locutorio, en que se agarra a los barrotes y no puede comunicarse con facilidad, simboliza la pérdida de la libertad de expresión. Su manifiesta preocupación está enfatizada por el encuadre, ya que se sitúa a la derecha, y su rostro serio contrasta con las sonrientes caras de las "Trece Rosas", asomadas al camión. De nuevo aquí, al final de los años 2000, evoluciona la imagen del encarcelamiento franquista que proporciona el cine: se hace más dramática, menos tópica, a medida que el espectador ya se ha acostumbrado a este subgénero: no queda más remedio que renovar los espacios estereotipados de la cárcel como son el patio y sus agradables conversaciones y creaciones (El Lápiz del carpintero, Las 13 Rosas) o las celdas que simbolizan el hacinamiento.

Quizás por eso, en 2019, la película Sordo sitúa la detención de Vicente en una iglesia: salimos del cliché de las galerías, para recuperar la memoria de las prisiones habilitadas, incluso en lugares religiosos. También salimos del plano corto que emociona al espectador, con un plano general, donde el personaje desaparece en el decorado sombrío, aunque está debajo de la luz "divina". No obstante, queda por saber si esta mediación de la memoria histórica, que se aleja del sentimentalismo e insiste en la individualidad y la soledad, tendrá un impacto mediático, puesto que, de las tres películas citadas, la más taquillera fue Las 13 Rosas, con 786.438 entradas y un Goya más que La voz dormida, mientras que Sordo apenas contó con más de 15.000 espectadores el año de su estreno.

\subsubsection{Ejecutados/as y asesinados/as}

Para concluir este recorrido, podemos destacar de qué manera se representa la muerte de estas víctimas. En general, se suele insistir en la sangre derramada y en los tiros de gracia de los fusilamientos, como elementos sobresalientes de un martirio casi épico. Una de las primeras películas de esta etapa, Silencio roto, se inicia con un primerísimo plano sobre las manos sangrientas de una víctima transportada a lomos de un caballo: son como la metonimia del ejecutado, ya no se trata de un cuerpo humano sino casi "desmembrado".

Más explícita aún es la escena del pelotón de fusilamiento al final de Las 13 Rosas, clímax de la epopeya dedicada a estas trece "mártires" del franquismo, que contrasta con el tratamiento de otro fusilamiento de cierre bajo la lluvia, al final de El Lobo. El efecto de perspectiva pone en valor a las víctimas, que quedan así por encima de los militares, y su ropa de color viva contrasta con la muerte que tarda en llegar. Asimismo, el episodio de la "Desbandá" a Almería (Bethune, 2004), que se relata en el documental de 
animación 30 años de oscuridad (2011), infunde en el espectador dramatismo y pathos a través de un plano que remite a la Mater Dolorosa, pero con papeles invertidos: la víctima es una mujer y el corazón dolorido del hombre que llora queda en el centro exacto del fotograma, gracias al punto de fuga. Por supuesto, no podemos pasar por alto los efectos especiales empleados para conmover al espectador de la más reciente Gernika, aunque el exceso de sensacionalismo pudo ser contraproducente si nos fijamos en sus 66.203 entradas.

En las películas que nos ocupan son numerosas las ejecuciones o, incluso, las muertes colaterales de la violencia franquista, como la del topo que se suicida por la ventana de su casa para huir de una detención segura, al final de Los girasoles ciegos. El pelotón de fusilamiento del que escapa Sánchez Mazas es una obsesión en Soldados de Salamina. Y el asesinato de Lorca, casi hecho metonimia de la violencia franquista, se convierte en un trauma psicológico, y genera el ejercicio de reescritura memorial de La luz prodigiosa. Sin embargo, el subgénero del cine de la memoria histórica terminó generando cierta saturación en el público -al igual que la novela de la memoria, como lo escribe irónicamente Isaac Rosa en Otra maldita novela sobre la guerra civil- y tuvo que reinventarse para seguir atrayendo.

\subsection{Víctimas resistentes, pero no héroes: ¿mediadores de otra memoria?}

La otra categoría de víctimas del franquismo que va cobrando importancia a lo largo de las dos últimas décadas de cine español es la de los "resistentes", en oposición a las víctimas represaliadas. La evolución de la imagen de estas víctimas que resistieron a la violencia conlleva cierta redefinición de la victimización y matiza su dimensión épica.

\subsubsection{Los maquis}

Si bien es cierto que los maquis aparecían, en el cine del franquismo, bajo la forma de unos delincuentes -a imagen y semejanza del estatus jurídico que tenían por la Ley de Bandidaje y Terrorismo (1947)-, la Transición les rindió un merecido homenaje, devolviéndoles la dimensión épica que les había sido negada (Martínez Álvarez, 2012: 240-243). La mitificación llegó a tal extremo que, a partir de 2010, presenciamos el proceso inverso, después de una década de casi ausencia. Si nos fijamos en el cartel de Silencio Roto, estrenada en 2001 y que tuvo hasta más éxito que Soldados de Salamina a nivel de entradas, vemos hasta qué punto se idealiza la figura del maquis interpretado aquí por Juan Diego Botto: un joven fuerte y guapo está sujetando el fusil en la mano izquierda y está siendo besado por una mujer, lo que pone en un primer plano el amor y relega la lucha política al segundo. Sin embargo, en esta película, ya notamos una 
mayor importancia de las mujeres y una dimensión más humana de los hombres atrapados en la sierra.

El proceso de desmitificación progresiva se amplifica en la década siguiente, a partir del estreno de Caracremada, un antibiopic sobre Ramón Capdevila, que murió asesinado por dos guardias civiles en 1963: salimos del estereotipo habitual del maquis, ya que el personaje no se corresponde con el típico joven guapo y heroico. Y esto tiene un precio: la película apenas alcanzó más de 2.000 entradas, frente a las más de 400.000 de Silencio roto. El maquis desmitificado no es tan vendedor ni atrayente para el público, como parece confirmarlo la recepción de la reciente ficción Sordo, que sin embargo recibió el premio especial Ferroz. El personaje de Anselmo, en Sordo, tampoco se corresponde con el estereotipo del maquis joven y atractivo.

El principal interés de esta película es que renueva el subgénero mediante la parodia del spaghetti western y los símbolos del antihéroe que, como lo indica el título, queda sordo tras un asalto al principio del filme. En efecto, se aprecian reiterados guiños al western: Anselmo empieza por robar a un señorito su caballo, su sombrero y su chaqueta de cuero, lo que le asemeja a un cowboy antifranquista; el capitán le dice al sargento que están "cazando indios", es decir maquis. Además, el ambiente del oeste queda reflejado por la música que acompaña los planos generales y escenas paródicas como la entrada sangrienta de la mercenaria en el bar, que renueva el tópico mediante la feminización del macho. Anselmo encarna la posibilidad perdida de vencer al franquismo que reinvindicaban los maquis -en una escena mata a unos franquistas y éstos le suplicanpero termina muriendo en la nieve, solo, cuando la invasión fracasa: evocando de manera alegórica la valiente pero imposible invasión del Valle de Arán. Así, vemos que a lo largo de los años, los maquis se volvieron más humanos y más realistas, menos heroicos aunque más auténticos. Otra figura de víctimas, mucho tiempo olvidada, que va siendo rehabilitada y dignificada como resistente antifranquista es la de los topos.

\subsubsection{Los topos}

En este sentido, es muy interesante observar la evolución de la representación del topo en la escena mediática a lo largo de la última década, a partir de tres películas. Hasta estrenarse en 2008 Los girasoles ciegos, adaptada de los relatos homónimos de Alberto Méndez, el topo era un actor del franquismo desconocido por el cine español. Sin embargo, en esta temprana evocación, la protagonista y principal víctima es su mujer y Salvador, que intenta violarla- ya que Ricardo aparece, incluso en el cartel de la película, en pijama, atrapado en la intimidad de la casa, y su único acto de resistencia es tirarse por la ventana cuando es delatado por Salvador y lo van a descubrir. Es un personaje secundario todavía, pero la película no dejó de ser muy bien recibida por el público y la crítica. 
El tema del topo también apareció en 2010 en la película Pan negro, aunque sólo de pasada: Farriol se esconde en la buhardilla de la granja y es descubierto por el alcalde falangista. Al año siguiente, el topo se convirtió realmente en protagonista cuando se relató la historia de Manuel Cortés, alcalde de Mijas, en la película documental de animación, 30 años de oscuridad que, desgraciadamente, no recibió una merecida atención. Se insiste en la larga espera de los treinta años (el espectador presencia cómo el franquismo le roba simbólicamente la vida) y en las condiciones de vida para quien vive emparedado en su propia casa.

Pero hubo que esperar hasta 2019, con La trinchera infinita, para que se rehabilitara con éxito la figura del mismo topo y de los topos en general, como víctimas dignas que resistieron a las represalias franquistas. Al igual que en Los Girasoles ciegos, la esposa desempeña un papel clave, lo que, una vez más, muestra el mayor protagonismo de las mujeres en este cine: de hecho, la actriz Belén Cuesta se llevó un Goya y Rosa se sitúa delante de su marido en el cartel de la película. Pero, esta vez, el marido, Higinio, no es una mera víctima pasiva sino que hasta mata al fascista que intenta violar a su mujer -un guiño interdiscursivo a Los girasoles ciegos, en la que el marido asistió impotente a esa violación- teniendo el valor de salir de su escondite y de enterrar el cadáver en el agujero.

De esta manera, los topos, que siempre fueron considerados menos valientes y heroicos que los maquis -eran casi su contrapunto- quedan rehabilitados en su dignidad, como lo simboliza el paseo final en que sale de su casa y es aceptado. Más allá de epopeyas y maniqueísmos, los maquis y los topos se convierten, por mediación de un cine más maduro, en figuras dignas de ser recordadas en toda su complejidad humana: "puede que no sea un héroe, pero no deja de ser una víctima" dice a Higinio su víctima (el que violó a su mujer) en un sueño. Puede que no sean del todo héroes ni resistentes los represaliados, los maquis y los topos, pero no dejan de ser víctimas a las que rendir homenaje, no sólo en conmemoraciones sino también a través de la pantalla. Y es lo que hacen los directores de estas películas, recurriendo a la cultura mediática con fines memorialistas.

\subsubsection{Nuevos elementos que relativizan el relato épico}

Podríamos terminar este viaje cinematográfico por la rehabilitación de las víctimas del franquismo concretando algunas estrategias que contribuyen a alejarlas del arriegado papel de mártires y héroes, propia de la épica, exaltación colectiva de hazañas (Labarthe, 2006: 273-275). El primer elemento que contrarresta la dimensión épica del cine de memoria sería la multiplicación de los biopics para contar la historia de la represión franquista desde los individuos que la vivieron. Así, La Fuerza de un silencio se centra en el músico Pau Casals; Buñuel en el Laberinto... en el fusilado Ramón Acín; Mientras dure la guerra en la evolución de las posturas de Unamuno frente al golpe de Estado fascista y la película de animación Josep, en el paso del dibujante Bartolí por los campos del sur 
de Francia. Esta representación cinematográfica de un nuevo individualismo es propia del cine hipermoderno según lo analiza Lipovetsky a través del término de "cineyó" (Lipovetsky, 2009: 205).

Por otra parte, se cuenta cada vez más la represión desde el dibujo, quizás en un intento de suavizar la crueldad de la violencia o de matizar la ilusión mimética del cine realista. Por eso, pasamos de numerosas adaptaciones de novelas en los años 2000 (como La lengua de las mariposas o El lápiz del carpintero) a la adaptación frecuente de cómics en los últimos años (como Sordo o El Fotógrafo de Mathausen) y presenciamos el auge de las películas de animación desde 30 años de oscuridad. Finalmente, podemos señalar la mayor internacionalización de los personajes (la mercenaria rusa de Sordo, los nazis de El Fotógrafo de Mathausen) y de las tramas (la investigación en Francia en Soldados de Salamina, las tramas paralelas entre España y Guinea Ecuatorial en Palmeras en la Nieve). Esa desterritorialización y transnacionalización como forma de "imagenmultiplejidad" (Lipovetsky, 2009: 101), facilita la decentración patriótica y corre en paralelo con la internacionalización del proceso de recuperación de la memoria histórica española en la última década: con la querella argentina o, desde 2019, la instauración del 5 de mayo como día de los españoles deportados.

\section{Estética de la violencia: evolución de unos símbolos mediáticos}

No sólo han evolucionado los modos de victimización para relatar la violencia franquista en el cine español reciente, sino que también va cambiando la manera de retratar la violencia y sus actores. Así, veremos cómo las películas de la última década renuevan la imagen de los verdugos, incluyendo a más mujeres, cómo no se limita a la violencia física y cómo, en caso de representarla, lo hace de manera más sutil para huir de la redundante escena del pelotón de fusilamiento.

\subsection{Renovación de los verdugos y las represoras}

\subsubsection{No sólo matan los falangistas}

Lo primero que llama la atención acerca de los verdugos, es que se van alejando de la imagen estereotipada que pudo tener en la Transición, si bien El Verdugo de Berlanga (1963) trató el tema con humor y complejidad. Igor Barrenetxea Marañón señala en particular que se dio "un papel excesivamente protagonista" a Falange como categoría mayoritaria de represor en películas de los años 2000 como Soldados de Salamina, El 
lápiz del carpintero o La buena nueva: esto conformó un "imaginario sesgado" ya que, aunque participó de manera activa y sustancial en la represión, la historiografía apunta que ésta fue coordinada por los militares (Barrenetxea Marañón, 2012: 11-12).

En efecto, los falangistas no fueron los únicos en reprimir y matar a los republicanos, y esto se va reflejando en el cine más reciente. Por ejemplo, en Pan negro, el guardia civil aparece en el momento de la detención junto al alcalde. Asimismo, en las películas sobre el topo Manuel Cortés, los civiles también están implicados en las delaciones y las violencias: la represión llega a ser asumida por vecinos y conocidos, como lo recalcan la perspectiva de la pistola apuntada en un primer plano de 30 años de oscuridad o la persecución obsesiva por parte de Gonzalo, que termina por entrar en la casa de Higinio décadas después, al final de La trinchera infinita.

\subsubsection{Y las mujeres también son represoras}

En los años setenta, las feministas denunciaron la infrarrepresentación y estereotipación de las mujeres en el cine de Hollywood, y deconstruyeron estos tópicos desde una mirada más femenina o militante (Trenzado Romero, 2000: 68). Aunque en materia de cine de la memoria contamos con pocas mujeres directoras, sí podemos hablar de cine feminista por parte de algunos directores que subvierten mecanismos machistas del cine clásico para dar más protagonismo a las mujeres, incluso en papeles poco usuales. En este sentido hay que interpretar la mayor presencia de mujeres entre los verdugos como un logro reciente. Las mujeres no sólo fueron víctimas pasivas de la violencia franquista sino también represoras activas, y el cine como mediación política lo refleja cada vez más.

El primer personaje que, quizás, mejor lo demuestre -si pasamos por alto la Topete de Las 13 Rosas por ser polémica, como veremos- es la Sor Serafines de La voz dormida. Este personaje representa la reeducación religiosa y la implementación de las teorías redencionistas del Patronato franquista (Gómez Bravo, 2008) en Ventas. En una escena de mucha tensión emocional, mientras las presas forman en el patio, pierde los papeles cuando una reclusa se niega a besar el pie del "muñeco" Jesús en Navidad, y termina apaleándola e insultando a todas: "todas ustedes son basura". Más complejo aún es el personaje ficticio de la Mercenaria en Sordo. Tuerta como Millán Astray, pelirroja, es una especie de Calamity Jane rusa que se caracteriza por su crueldad extrema, mucho más que el capitán Bosch. Tortura a Vicente con precisión, después de matar a todos los soldados del bar (en una parodia de western), y termina por humiliar y violar a Rosa con un pretexto falsamente feminista: "odio las mujeres como tú, que son sólo la sombra de su marido".

La escena de violación constituye el clímax de la película y, a pesar de rozar el maniqueísmo, renueva el estereotipo del torturador caricaturesco, mediante la violación de una mujer por una mujer armada. El símbolo fálico de esta pistola -que hace 
eco a la porra de Sor Serafines- permite jugar con los códigos de género y la homosexualidad, y se ve reforzado por la dilatación de esta escena muy violenta, observada por Anselmo, alter ego del espectador voyerista, a través de sus prismáticos. El sadismo refinado de la represora se vislumbra cuando le devuelve el escupitajo que recibió de su marido Vicente y limpia la sangre de la pistola en la cara de la víctima. Los juegos de la cámara, usando un picado para subrayar la dominación para con la víctima, y un raccord seguido de un plano invertido, para recrear el trastorno emocional, acompañan el silencio y luego la música de tonalidad triste. La mercenaria aparece de forma poco verosímil, ya que es una excombatiente de Stalingrado que viene a ayudar a los franquistas: parece un personaje de cómic o de una película de Tarantino y, si bien internacionaliza la trama, lo hace de forma inexplicable; tan inexplicable como su violencia irracional. Pero más allá de las nuevas figuras de represores más o menos logradas, también evoluciona la estética de la violencia a nivel de los símbolos de una represión plural.

\subsection{La violencia, más allá de la represión física}

La violencia es el uso intencional de la fuerza física, pero también puede consistir en amenazas a través del lenguaje, en la acción o la inacción. En este sentido se entiende que la Ley de Memoria Histórica, ya en 2007, promovía retirar los vestigios visuales de la dictadura como pueden ser las placas dedicadas a los actores del golpe de Estado²: la violencia simbólica de estos vestigios o la violencia verbal de los discursos que justifican el franquismo, son agresiones para los supervivientes o sus familiares. Exploraremos aquí brevemente dos tipos de violencia más sutiles que la violencia física pero igual de importantes a la hora de retratar el impacto del franquismo a los espectadores.

\subsubsection{La violencia verbal: ¿enfrentamiento de las dos Españas?}

La primera película de memoria que abre este periodo, La lengua de las mariposas, se cierra en la escena final en el prototipo de la violencia verbal más encarnizada. Más que la pedrada final del niño que se deja arrastrar por la brutalidad que le rodea, nos interesa sobre todo la retahíla surrealista de insultos que la precede, donde aparecen palabras enseñadas por el maestro ("Ateo, rojo, ornitorrinco, espiritrompa"): simboliza el lenguaje desvirtuado por el franquismo, la sustitución de la cultura republicana por la ignorancia. Este enfrentamiento de las dos Españas, sin diálogo posible, es lo que que procura denunciar Amenábar en Mientras dure la guerra: observamos una evolución funesta desde la discusión cordial y argumentada entre Miguel y Salvador, hasta el enfrentamiento del Día de la Raza, cuya violencia verbal se enfatiza (“Al paredón" le gritan) frente a la diatriba de Unamuno. Según el diario $A B C$, una licencia

\footnotetext{
${ }^{2}$ El proyecto de Ley de Memoria Democrática prevé además resignificar el Valle de los Caídos, ilegalizar
} las asociaciones franquistas, amparar las exhumaciones y anular las sentencias franquistas. 
cinematográfica explicaría la exageración de este episodio histórico (Cervera, 2019), del que conservamos pocas fuentes directas.

\subsubsection{Violencias simbólicas de la represión franquista}

Más compleja y variada es la violencia simbólica del franquismo que, por supuesto, queda reflejada en los episodios en que se obliga a la población a hacer el saludo fascista: por ejemplo, lo hacen dos niños y unos campesinos al paso de los militares y requetés, en el minuto trece de Las 13 Rosas. También podemos citar otros tipos de violencia como la cultural -simbolizada por la censura de libros o por el enfrentamiento con Unamuno en Mientras dure la guerra- y la institucional, simbolizada por el cambio de bandera republicana, al principio de la película Mientras dure la guerra, por la monárquica, aunque ajada al final.

Sin embargo, aparece un nuevo tipo de violencia simbólica más atípico, que coincide con el tardofranquismo y que queda retratada en Palmeras en la nieve: la violencia -incluso la violación- colonial en Guinea ecuatorial durante los años sesenta. No sólo se insiste en los latigazos recibidos, sino también en un racismo cada vez más cuestionado ("Ya nos habéis explotado lo suficiente, tarde o temprano tendréis que marcharos") y que configura, desde el presente de la búsqueda de memoria familiar, el resentimiento inicial entre Clarence y su futuro amante. Se puede leer el desenlace como el alcance de una memoria sin deseo de venganza, que logra reparar las heridas del pasado y abrir paso a una nueva convivencia: lo mismo que piden las asociaciones de víctimas del franquismo desde los años 2000. La película cumplió entonces con su papel de mediador de la memoria, y recibió una buena acogida por parte de los espectadores (731.486 entradas) y de la crítica (dos Goyas).

\subsection{Mostrar la muerte de otra forma}

Al cabo de este panorama estético de la violencia, comprendemos que la mediación de la represión franquista por el cine no sólo depende de la representación de la violencia física. Pero tampoco puede prescindir de ella, a pesar de correr el riesgo de ser otra maldita película sobre la Guerra civil. Una de las estrategias, en algunas de las películas más recientes, consiste por tanto en huir de los tópicos, en particular el del pelotón de fusilamiento. Puede ser que el espectador se haya cansado de cierto tipo de cine sobre el franquismo, como lo muestra la evolución de las entradas por películas a partir de 2008: las películas centradas exclusivamente sobre la represión casi no superan las 300.000 entradas, por muy reconocidas que sean por la crítica (como La voz dormida, con tres Goyas). En la filmografía en anexo, las que realmente tienen éxito a lo largo de los años 2010 son películas que evocan muy de pasada las huellas del franquismo, como La isla mínima o Palmeras en la nieve. 
Hubo que esperar hasta 2019, con un nuevo boom del cine de memoria, y el estreno de Mientras dure la guerra para superar el millón de espectadores en menos de un mes (Efe, 2019), y acercarse a los dos millones en el año. Y, sin embargo, esta película casi prescinde de la violencia física, como lo recuerda Amenábar en los extras del DVD: sólo la sugiere de forma muy sutil, lo que quizás coincida con una demanda implícita del público. Lo hace mediante un aumento progresivo de la tensión, paralelamente a la toma de consciencia de Unamuno: los disparos en Salamanca, los muertos en la cuneta, el asesinato lejano de Lorca, la detención más cercana de Salvador como clímax que desemboca en su reacción: "tenéis fuerza bruta de sobra", lo que sirve para vencer pero no basta para convencer. Así, la única escena que realmente muestra los estragos físicos de la represión franquista es el trávelin y contrapicado sobre dos cuerpos tirados en una cuneta. Apenas sugiere la dimensión mortífera del recorrido de los legionarios de Millán Astray: están tumbados, parecen dos amantes dormidos entre trigales y solo adivinamos que están muertos por unas pocas manchas de sangre y el brazo alargado del hombre.

También encontramos otra forma de evocar la muerte, de manera más original, al principio de La trinchera infinita. Esta película se abre con la fuga del protagonista para escaparse de los falangistas que intentan deternerlo. Termina escondiéndose en un pozo junto a otros compañeros, y su charla los delata. El director opta entonces por representar la muerte de manera indirecta, aunque muy violenta, mediante la posición de la cámara, la banda de sonido y el tratamiento de la imagen. Primero, insiste en la indefensión de las víctimas -cuya risa se ve truncada por la aparición de los falangistas asomados al pozo- gracias a la angulación en picado. Luego, la banda de sonido permite sumergir al espectador con precisión en la matanza, ya que se pueden contabilizar once tiros en total. Casi no se muestra el momento de la muerte de los compañeros, ya que, durante los tiros, la cámara está enfocada con un plano medio corto en el miedo del protagonista, refugiado en un recoveco del pozo. De esta manera, es aún más impactante el contraste posterior con el plano de conjunto, en picado, de los cuerpos yacentes en un baño de sangre. Gracias a la cámara subacuática, el espectador observa los cuerpos flotando y el derrame casi lírico de sangre que va contaminando el agua, mientras Higinio intenta hacerse un torniquete. Sin duda, esta manera innovadora de simbolizar y sugerir la violencia franquista puede atraer a otro público hacia el cine de la memoria. Si no fuera por el éxito paralelo de Mientras dure la guerra, tal vez habría alcanzado La trinchera infinita el nivel de entradas de La voz dormida. 


\section{Relatos enfrentados: mediación de los debates ideológicos en torno a la memoria histórica}

La representación de la violencia y sus actores han ido evolucionando en el cine desde 1999. Como explicábamos, esta evolución mediática responde a una demanda social, política y cultural en un contexto de recuperación de la memoria histórica y mayor igualdad de género. Pero la mediación de la industria cinematográfica puede ir más allá de las representaciones y hacerse eco de los debates ideológicos de la sociedad.

\section{1 ¿Salir del sentimentalismo y del sensacionalismo?}

El primer enfrentamiento entre posturas ideológicas que se vislumbra en el cine de este periodo remite al equilibrio entre el sentimentalismo para deleitar al espectador y el deber de fidelidad a la memoria histórica. Para entender este conflicto podemos analizar la ruptura manifiesta que se establece entre el estreno de Las 13 Rosas en 2007 y el de La voz dormida en 2011. En primer lugar, Las 13 Rosas cuenta con muchos tópicos románticos, reforzados por el uso de la música en la banda sonora, que tienden a fomentar en la mente del espectador una visión idealizada de la epopeya republicana, castigada por el franquismo. A modo de ejemplo, la escena final en que las jóvenes, a punto de ser fusiladas, se abrazan delante de sus verdugos en el pelotón suena a "épica de pastel", una épica que, según la escritora Belén Gopegui, pinta "con tonos épicos lo que carece de una épica real"' (Gopegui, 2006).

La dilatación de esta escena de despedida -entre las protagonistas y con el espectadorque parece no terminar nunca, se relaciona además con lo que Lipovetsky conceptualiza como hiperbolización de la "imagen-exceso", según la cual la lentitud es utilizada como recurso retórico en medio de un bombardeo visual y una intensificación de las sensaciones del espectador (Lipovetsky, 2009: 74). Observamos también ese exceso visual, esa búsqueda de sensacionalismo en la película Gernika, del director vasco Koldo Serra pero producida por los Estados Unidos. No recibió la acogida esperada, como lo subraya Javier Ocaña en El País:

En principio resulta chocante que, en 2016, y siendo Gernika la primera aproximación de la historia del cine a la masacre, el tono sea el del melodrama romántico clásico. [...] La banda sonora de Fernando Velázquez, remarcando siempre cada suceso, apenas se detiene, y la cámara de Serra gira y gira alrededor de los personajes, entrando y saliendo de habitaciones y calles con tanta agilidad como falta de freno. Travellings constantes, infinidad de tomas con grúa, 
helicóptero (o dron), aderezos digitales. Como una coreografía que envuelve a los personajes pero que (casi) nunca los mira de frente $y$, aún más, a su interior. (Ocaña, 2016)

Este crítico la califica incluso de "película de superhéroes" y lamenta que se quede en "la superficie de la tragedia", "sin lograr penetrar en el drama, en la ignominia ni en las tripas" (Ocaña, 2016). La saturación de imágenes, sensaciones y sentimientos melodramáticos podrían ser contraproducentes y alejar al espectador de la autenticidad de la tragedia.

Por eso, La voz dormida opta por una mayor verisimilitud acerca de las condiciones en la cárcel de Ventas, en comparación con Las 13 Rosas. No deja de modificar detalles, como la letra de la canción de cuna ("no te asustes por mi pena") pero, aún así, sigue siendo más verosímil que algunas escenas de Las 13 Rosas, como la alegre y larga entonación en medio del patio de la canción de época "Cárcel de Ventas, hotel maravilloso" o el baile de claqué sin represalias, que contrastan, por ejemplo, con el concierto clandestino en los lavabos que queda retratado en el cómic Cuerda de presas (García, 2017: 24-25). Las risas durante la misa, el episodio de las ratas, la cacerolada son toques de humor que desentonan con la seriedad de la represión y amenizan la realidad que relatan los historiadores.

El personaje que mejor demuestra esa licencia cinematográfica es, sin duda, la directora de Ventas conocida como la Topete, que parece tan humana que casi llora por la muerte de Blanca: en cambio, La voz dormida procura mostrar en la pantalla una Topete más austera, bastante cercana a la que está descrita por los testigos y los historiadores (Hernández Holgado, 2011: 483-490). Para terminar con esta comparación, podemos añadir que La voz dormida, al igual que la novela homónima, asume un discurso menos despolitizado: la declaración de lucha "Resistir es vencer" de la novela (Chacón, 2002: 213) se convierte en "Entereza y resistencia" en la película, pero sin perder su esencia. De hecho, el epílogo con la voz en off de la sobrina, que incita a actuar y se proyecta en el futuro, contrasta con la visión conmemorativa del final de Las 13 Rosas, en que se lee la carta de capilla de Blanca. Es difícil saber cuál de estas películas ha tenido más éxito, ya que los niveles de recepción son equiparables, pero se dirigen a un público diferente y deben entenderse en su contexto mediático de origen.

\section{2 ¿Salir del cainismo y del maniqueísmo?}

Aparte del sentimentalismo y del sensacionalismo, otro de los reproches que se ha podido hacer a varias películas de los años dos mil y que las posteriores parecen intentar corregir es el de un maniqueísmo excesivo. Al querer ejemplificar en la pantalla la violencia franquista, ciertas producciones insisten en el mito cainita de las dos Españas, heredado del franquismo para justificar la Guerra civil y su "Cruzada" contra el desorden 
del Frente Popular. Por ejemplo, el actor Sergi López suele encarnar a personajes franquistas, viriles y antiheroicos: es el estereotipo del policía malo en Pan negro y el sádico coronel Vidal en el Laberinto del fauno, que mata a campesinos que cazaban conejos, así como al doctor Ferreiro. "Lástima" le dice al tartamudo que no pudo contar hasta tres y la crueldad extrema que se le asocia queda reforzada por el fundido en negro tras la bofetada. Lo que recalca Igor Barrenetxea en "La violencia franquista en el cine de ficción" acerca de iAy Carmela! de Saura podría aplicarse a la mayoría de los verdugos franquistas de la primera década de los 2000: transmiten una "atinada visión de las dos Españas, aunque enfatizando [...] el lado más perverso de los nacionales". Y como lo recuerda acertadamente, ocurrió el mismo fenómeno con el cine sobre el nazismo hasta la polémica del Hitler demasiado "humano" en El Hundimiento (2004) y todo esto pudo brotar después de "una atenta valoración de las víctimas" (Barrenetxea, 2011: 4-5). Veremos cómo, después de dos décadas de cine de la memoria en España, está empezando a ver la luz algo parecido respecto a Franco, aunque no guste a todos.

Pero, primero, detengámonos en la evolución de este maniqueísmo, pasando de Sergi López a Asier Etxeandia, que juega con el personaje del "malo" en Sordo, pero de manera bastante diferente. En esa reciente película española del oeste, se esfuman las tradicionales fronteras del western entre buenos y malos: el franquista Santiago resulta ser más bondadoso que algunos maquis republicanos, y Anselmo lleva el atuendo del malo, un poco por fatalidad, e incluso tiene una relación con la mujer de su amigo Vicente. Cuestionando el mito cainita y el maniqueísmo, volvemos, por tanto, al llamamiento de Amenábar, en Mientras dure la guerra, por un diálogo posible. Durante la discusión entre Salvador y Miguel de Unamuno, brotan argumentos casi estereotipados propios de las dos Españas pero, aunque están de espaldas, hay un diálogo posible que en cambio no lo es en el Paraninfo. Y cuando Amenábar rehúye de maniqueísmos y pide más diálogo en su película, lo hace pensando en la España actual: "el cine histórico siempre habla del presente" recuerda José Luis Sánchez Noriega (Sánchez Noriega, 2016: 307). Y aquí Amenábar también remite, como telón de fondo, a los enfrentamientos entre memorias reavivadas, en particular desde el traslado de Franco de Cuelgamuros en 2019.

\section{3 ¿Salir de la equidistancia y del revisionismo?}

Una última crítica que se puede hacer al reciente cine español, como mediador de la memoria de la represión franquista, es la equidistancia que emerge de algunas películas. Este concepto, aplicado primero a la narrativa de la memoria y apoyándose en una cita de Andrea Greppi, es definido por David Becerra Mayor como "la proyección de la imagen de los dos bandos enfrentados, repetida con buenas o malas intenciones a lo largo de los años, [que] alude al odioso postulado de la simetría entre las dos caras de una moneda o entre las dos bordas -las dos bandas- de un barco", equiparando de esta 
manera el gobierno legítimo de la República con la facción de los golpistas (Becerra Mayor, 2015: 203), como si tuvieran la misma responsabilidad.

El principal ejemplo de esta equidistancia en el ámbito del cine sería la adaptación de Soldados de Salamina de Javier Cercas por David Trueba en 2003, que tuvo tanto éxito como el libro. La principal diferencia entre la novela y la película, es que ésta feminiza -de nuevo en un intento de mediación hacia la igualdad de género- al narrador. Por tanto, relata la indagación de una escritora y profesora sobre la memoria de la Guerra civil española que "se mezcla con una sentida reivindicación de los anónimos luchadores contra el fascismo y con retazos de la historia del dirigente falangista Sánchez Mazas, detenido por las tropas republicanas" (Gubern, 2009: 485). Si bien, en algunos aspectos, Trueba procura hacer más evidente el contraste entre fascistas y republicanos, en su conjunto conserva el "quiasmo de la historia" y la equiparación de "bandos" por los que muchos especialistas tacharon la novela de revisionista (Delage, 2009). Este peligroso "quiasmo" inaugural consiste en equiparar la muerte del republicano Antonio Machado, exiliado en Colliure, con el fusilamiento fallido del futuro ministro de Franco y cofundador de Falange, Sánchez Mazas: "me disponía a escribir el consabido artículo rutinario cuando me acordé de Sánchez Mazas y de que su frustrado fusilamiento había ocurrido más o menos al mismo tiempo que la muerte de Machado, solo que del lado español de la frontera". Pero poner a estos dos escritores a la misma altura a nivel ideológico es una mediación política engañosa para el lector -y el espectador- ya que se hace gracias a unos atajos del tipo "nadie sabe ganar la guerra con dignidad" o "nadie merece morirse", en los que se basa la equidistancia supuestamente despolitizada.

Lo que nos interesa es que, al adaptar la novela al cine, Trueba conservó esa equidistancia -y el "quiasmo de la historia" inicial, a través de la lectura del artículo por su autora- quizás no tanto por falta de distancia, sino porque es la esencia del mensaje de la novela: todos fueron malos, todos tienen la culpa, pero existen algunos hombres buenos en cada bando, como Miralles. El juego de deconstrucción de David Trueba se centra sobre todo en la mofa respecto al "empacho" de memoria histórica ("La guerra civil otra vez no, por favor" le responde Lola Cercas a su jefe) y en la estructura del libro, desgranando los recuerdos de la guerra desde el presente de enunciación. Esto demuestra hasta qué punto el cine puede ser un arma de doble filo, como recuerda Lipovetsky al final de La Pantalla global, y más aún cuando difunde, a mayor escala por llegar a más público que el libro, una concepción revisionista del franquismo. Cuando importa más el presente que el pasado, como ocurre con el cine histórico actual según Lipovetsky, la ficción corre el riesgo de distorsionar la realidad histórica con fines de mediación política: "el cine hipermoderno presentiza deliberada y abiertamente el espectáculo del pasado" (Lipovetsky, 2009: 168), hablando de ayer para decir algo de hoy. 
Aunque la equidistancia propiamente dicha solo se puede aplicar al cine sobre la Guerra civil, por implicar dos bandos, también puede existir esta tentación de equiparar a franquistas y antifranquistas en el cine sobre la dictadura. Para prolongar esta reflexión podemos plantearnos hasta qué punto rehabilitar a los franquistas disidentes e, incluso, desdiabolizar al verdugo del pasado, a través de la cultura mediática, puede ser interpretado como negacionismo en el presente. Es lo que ocurre con algunas películas recientes, como La encrucijada de Ángel Sánz Britz, la primera en interesarse completamente, en 2015, por una figura referencial de "buen franquista". Ese biopic cuenta la historia de un justo que fue apodado el "Schindler español", a partir del testimonio de un salvado sefardí, Jaime Vandor. Incluso la aplaudida Mientras dure la guerra recibió críticas, por rozar con la equidistancia, en el festival de cine de San Sebastián. “¿Qué significa ser justo cuando en un lado hay miles de muertos? ¿Es justicia mostrar la faceta humana de Franco más subrayada que la de asesino?" se interroga Begoña Piña antes de entrevistar a Amenábar. Es curiosa, al respecto, la escena en que Franco sintetiza con voz suave su proyecto de eugenesia: "hacen falta años para limpiar esto". Pero el director insiste en que quiso que "se identificaran las dos Españas" en la discusión entre Salvador y Miguel porque los españoles tienen "una especie de orfandad de identidad" y por eso utiliza la bandera al principio y al final, y concluye: "no estoy a la misma distancia de Unamuno que de Franco" (Piña, 2019). La expresión que utiliza para justificarse es muy importante, puesto que es precisamente lo contrario de la equidistancia que cuestionábamos. En cualquier caso, como explicamos anteriormente con el paralelismo que establece Igor Barrenetxea con el cine sobre el nazismo, esta capacidad de superar el maniqueísmo y de explorar la complejidad humana de los verdugos, sin caer en la equidistancia absoluta, es sin duda una prueba de madurez del cine español, tras dos décadas de atención renovada a las víctimas.

Concluyamos esta exploración del cine del siglo XXI, que ha ido mediando por concienciar al público acerca de la violencia de la dictadura franquista. Desde el estreno de La lengua de las mariposas hasta el éxito de Mientras dure la guerra, han transcurrido veinte años durante los que el cine, como actor fundamental de la cultura mediática, ha pujado por transmitir en la pantalla su memoria plural del franquismo. Lo ha hecho en un contexto de recuperación de la memoria histórica y de lucha por la igualdad de género, por lo que aparecen cada vez más mujeres víctimas así como represoras. A medida que ha ido madurando, este cine se ha hecho más verosímil y más innovador, sea desde el punto de vista de los personajes, de la representación de la violencia o de los relatos que emergen de estas mediaciones. Aunque no siempre se corresponda con el mismo grado de recepción, podemos destacar varios logros, como el mayor protagonismo de las mujeres con la configuración de dualidades (Pepita/Tensi frente a la monja Serafines en La voz dormida, Rosa versus la mercenaria en Sordo) o de ayudantes que permiten la evolución del protagonista (Rosa en La Trinchera infinita, la viuda del alcalde y la hija de Unamuno en Mientras dure la guerra); la paulatina desmaniqueización de los verdugos, sin (re)caer en la equidistancia (Enrique en Miel de 
naranjas, o la iglesia víctima y verdugo en La Buena nueva); la ampliación de temas y enfoques, con una internacionalización del franquismo. Sin embargo, todavía quedan temas pendientes, como los niños robados (sólo se evoca en la poca exitosa Estrellas sin alcanzar o el documental El silencio de otros) y los campos de concentración: aparecen los campos de trabajo del Canal de los presos en Sevilla en Miel de naranjas, y el Valle de los Caídos apenas sirvió de decorado en Los años bárbaros en 1998 y en Balada triste de trompeta en 2010, tratando con humor sus calaveras y sus esculturas de granito bajo la cruz. Si la "cinevisión" (Lipovetsky, 2009: 320-321) tiene el poder de cambiar la percepción del franquismo, entonces las películas del siglo XXI habrán sido valiosas mediaciones para que se lea esta página de la historia y se cierren las heridas.

\section{Referencias bibliográficas}

ADORNO, T. y HORKHEIMER, M. (1998): Dialéctica de la ilustración. Fragmentos filosóficos, Madrid, Trotta.

BARRENETXEA MARAÑóN, I. (2019): "Revenge. La violencia franquista en el cine de ficción” en Historia Actual Online, no 49 (1), 2019, pp. 33-44.

- (2012): “Cine, represión y Memoria Histórica”, en Ibarra Aguirregabiria, A. (coordinadora), No es país para jóvenes, Vitoria, Instituto Valentín Foronda, pp. 120.

- (2011): "Víctimas de la represión franquista en el cine: un esencial activo del imaginario social" en Primer Congreso de Víctimas del Franquismo, 20-22 de abril de 2012, Rivas Vaciamadrid. Disponible en internet (3-12-2011): http://www.congresovictimasfranquismo.org/wp-content/uploads/2011/12/3.Igor-Barrenetxea-V\%C3\%ADctimas-de-la-represi\%C3\%B3n-franquista-en-elcine.pdf

BECERRA MAYOR, D. (2015): La Guerra Civil como moda literaria, Madrid, Clave Intelectual.

BETHUNE, N. y MAJADA NEILA, J. (2004): El crimen de la carretera Málaga-Almería (febrero de 1937), Benalmádena, Caligrama ediciones.

BORDWELL, D. y THOMPSON, K. (2003): El arte cinematográfico: una introducción, Barcelona, Paidós Ibérica.

CERVERA, C. y CABANELAS, L. M. (2019): “Los 18 errores históricos de Mientras dure la guerra, la película sobre Franco y Unamuno de Amenábar" en abc.es, 29 de octubre de 2019. Disponible en internet (29-10-2019): 
https://www.abc.es/historia/abci-17-errores-historicos-mientras-dure-guerrapelicula-sobre-franco-y-unamuno-amenabar-201909292254 noticia.html

CHACÓN, D. (2002): La voz dormida, Barcelona, Alfaguara.

DELAGE, A. (2019): "Javier Cercas historien. Pour une approche critique de la fiction d'archive contemporaine", en Fabula / Les colloques, "Les écritures des archives : littérature, discipline littéraire et archives". Disponible en internet (15-9-2019): http://www.fabula.org/colloques/document6328.php

EFE, "Mientras dure la guerra supera el millón de espectadores en veinte días" en efe.com, 21 de octubre de 2019. Disponible en internet (21-10-2019): https://www.efe.com/efe/espana/cultura/mientras-dure-la-guerra-supera-elmillon-de-espectadores-en-veinte-dias/10005-4091840

FERNÁNDEZ DÍEZ, F. y MARTÍNEZ ABADÍA, J. (1999): Manual básico del lenguaje y narrativa audiovisual, Barcelona, Paidós.

GARCÍA, J. (2017): Cuerda de presas, Bilbao, Atisberri.

GÓMEZ BRAVO, G. (2008): La redención de penas: la formación del sistema penitenciario franquista, 1936-1950, Madrid, Catarata.

GÓMEZ RODA, J. A. (2005): "La tortura en España bajo el franquismo: testimonio de torturas durante la dictadura y la transición a la democracia" en Pasajes: Revista de pensamiento contemporáneo, №. 17, 2005, pp. 49-67.

GOPEGUI, B. (2006): "La responsabilidad del escritor en los relatos de victoria y derrota", IV Encuentro en Defensa de la Humanidad, Anzoátegui (Venezuela), juin 2006. Disponible en internet (11-6-2006): https://rebelion.org/la-responsabilidad-delescritor-en-los-relatos-de-victoria-y-derrota/

GUBERN, R. y MONTERDE, J. E. (2009): Historia del cine español, Madrid, Cátedra.

GUSTRÁN LOSCOS, C. (2015), El franquismo en el cine español (1975-2000): la representación cinematográfica de la dictadura franquista, Tesis de Doctorado, Zaragoza, Universidad de Zaragoza.

HERNÁNDEZ HOLGADO, F. (2011): La prisión militante: las cárceles franquistas de mujeres de Barcelona y Madrid (1939-1945), Tesis de Doctorado, Madrid, Universidad Complutense.

LABARTHE, J. (2006): L'épopée, París, Armand Colin.

LIPOVETSKY, G. y SERROY, J. (2009): La pantalla global. Cultura mediática y cine en la era hipermoderna, Barcelona, Anagrama. 
MARTíNEZ ÁLVAREZ, J. (2012): "Las películas sobre el maquis español: de la historia oficial a la memoria histórica" en Cuadernos de Historia Contemporánea, no 34, 2012, pp. 225-250.

NÚÑEZ, G. (2019): “La Plataforma Millán-Astray denuncia mentiras y odio en la nueva película de Amenábar" en larazon.es, 14 de junio de 2019. Disponible en internet (14-6-2019): $\quad$ https://www.larazon.es/cultura/la-plataforma-millan-astraydenuncia-mentiras-y-odio-en-la-nueva-pelicula-de-amenabar-PO23787585/

OCAÑA, J. (2016): "La superficie de la tragedia" en elpais.com, 9 de septiembre de 2016. Disponible en internet (9-9-2016): https://elpais.com/cultura/2016/09/07/actualidad/1473260767 410625.html

PIÑA, B. (2019): “Alejandro Amenábar: No estoy a la misma distancia de Unamuno que de Franco, pero quería ser justo y no cargar las tintas" en publico.es, 27 de septiembre de 2019. Disponible en internet (27-9-2019): https://www.publico.es/culturas/dure-guerra-alejandro-amenabar-no-distanciaunamuno-franco-queria-justo-no-cargar-tintas.html

SÁNCHEZ NORIEGA, J. L. (2016): “La prisión, espacio cinematográfico y lugar de memoria en el cine español" en Cuadernos de Historia Contemporánea, no 38, 2016, pp. 303-323.

TRENZADO ROMERO, M. (2000): "El cine desde la perspectiva de la Ciencia Política" en REIS: Revista Española de Investigaciones Sociológicas, no 92, 2000, pp. 45-70. 


\section{Anexo: filmografía}

\begin{tabular}{|c|c|c|c|}
\hline Título & Año & Entradas en el año & Premios \\
\hline La lengua de las mariposas & 1999 & 1.181 .542 & $\begin{array}{l}2 \text { (Goya y Circ. Escrit. Cine. } \\
\text { Mejor guion) }\end{array}$ \\
\hline Silencio roto & 2001 & 429.086 & $\begin{array}{l}1 \text { (Circ. Escrit. Cine mejor } \\
\text { actriz secundaria) }\end{array}$ \\
\hline La luz prodigiosa & 2002 & 70.717 & \\
\hline El viaje de Carol & 2002 & 356.702 & $\begin{array}{l}2 \text { (Oso de cristal, premio del } \\
\text { Público de Nantes) }\end{array}$ \\
\hline El lápiz del carpintero & 2003 & 169.813 & 2 (festival Mar de Plata) \\
\hline Soldados de Salamina & 2003 & 424.967 & 1 Goya (fotografía) \\
\hline Para que no me olvides & 2005 & 80.418 & \\
\hline El laberinto del fauno & 2006 & 1.346 .853 & $\begin{array}{l}21 \text { ( } 3 \text { Óscars, } 7 \text { Goyas, } 3 \\
\text { BAFTA, premio S. Jordi, } 10 \\
\text { premios Ariel) }\end{array}$ \\
\hline Las 13 rosas & 2007 & 786.438 & $\begin{array}{l}4 \text { Goyas (actor reparto, } \\
\text { música, foto., vestuario) }\end{array}$ \\
\hline La buena nueva & 2008 & 78.383 & \\
\hline La mujer del anarquista & 2008 & 68.163 & \\
\hline Los girasoles ciegos & 2008 & 710.318 & $\begin{array}{l}6 \text { (Goya guion adaptado, } 2 \\
\text { premios Cartagena) }\end{array}$ \\
\hline Estrellas que alcanzar & 2010 & 25.228 & \\
\hline Caracremada & 2010 & 2.238 & $1 \mathrm{~S}$. Jordi opera prima \\
\hline Pan negro & 2010 & 138.579 & 25 (9 Goyas, 13 Gaudí) \\
\hline Balada triste de trompeta & 2010 & 236.888 & 5 (2 Goyas, 2 Venecia) \\
\hline La voz dormida & 2011 & 313.203 & 6 (3 Goyas, Concha plata) \\
\hline 30 años de oscuridad & 2011 & & \\
\hline Al final de la escapada & 2011 & 246 & \\
\hline Miel de naranjas & 2012 & 62.372 & \\
\hline Silencio en la nieve & 2012 & 65.483 & \\
\hline Los colonos del caudillo & 2013 & & \\
\hline La isla mínima & 2014 & 1.030 .010 & 30 (10 Goyas) \\
\hline Palmeras en la nieve & 2015 & 731.486 & 4 (2 Goyas) \\
\hline El destierro & 2015 & 566 & \\
\hline
\end{tabular}




$\begin{array}{llll}\text { La encrucijada de Á. S. Britz } & 2015 & 507 & \\ \text { Gernika } & 2016 & 66.203 & \\ \text { La fuerza de un silencio } & 2017 & & 4 \text { (premios Gaudí) } \\ \text { El fotógrafo de Mathausen } & 2018 & 400.326 & 1 \text { Premio especial Feroz } \\ \text { Sordo } & 2018 & 15.289 & 4 \text { (Goya documental) } \\ \text { El silencio de otros } & 2018 & 23.497 & 6 \text { (Goya animación) } \\ \begin{array}{l}\text { Buñuel en el laberinto de las } \\ \text { tortugas }\end{array} & 2019 & 8.630 & 8 \text { (5 Goyas) } \\ \text { Mientras dure la guerra } & 2019 & 1.907 .356 & 10 \text { (2 Goyas) } \\ \text { La trinchera infinita } & 2019 & 228.733 & \\ \text { Maquis } & 2019 & & \\ \text { Josep } & 2020 & & \end{array}$

